\title{
Dai Chinese
}

National Cancer Institute

\section{Source}

National Cancer Institute. Dai Chinese. NCI Thesaurus. Code C158176.

A Chinese person from the Dai (including several different Tai-speaking groups

historically referred to as Bai-yi) ethnic group. 